\title{
Controlling of $2 \mathrm{MW}$ Horizontal Axis Wind Turbine by Using MATLAB for Ashegoda Wind Farm North of Ethiopia, Tigray
}

\author{
Gizachew Dereje \\ Mechanical Engineering, University of Gondar, Institute of Technology, School of Mechanical Engineering, Gondar, Ethiopia \\ Email address: \\ anasamu120@gmail.com \\ To cite this article: \\ Gizachew Dereje. Controlling of 2MW Horizontal Axis Wind Turbine by Using MATLAB for Ashegoda Wind Farm North of Ethiopia, \\ Tigray. American Journal of Modern Energy. Vol. 7, No. 2, 2021, pp. 13-21. doi: 10.11648/j.ajme.20210702.11
}

Received: December 12, 2020; Accepted: April 9, 2021; Published: April 26, 2021

\begin{abstract}
Wind is progressively being utilized to give a portion of the world's power. Points of interest of wind created power incorporate zero emanations and zero fuel cost. In any case, wind speed differs time to time, at a given time the controller can't handle the most extreme measure of intensity delivered by a turbine. An alternate rule utilized for ideal plan than that utilized for other gear where the pace of power creation can be controlled up to the hardware most extreme rating. The ideal plan for a wind turbine working in each wind asset is the plan that delivers the most electrical energy for a given capital expense. During high winds the particular plan boundaries and control frameworks should restrict the force variance to stay away from harm to the wind turbine. Thusly we should utilize distinctive control frameworks. The reason for the control arrangement of a wind turbine is to deal with the protected, programmed activity of the turbine. From these idea we can lessens working expenses, gives steady unique reaction and improved item quality, and assists with guaranteeing wellbeing. This activity is generally intended to augment yearly energy catch from the wind while limiting turbine loads. In this paper the controlling arrangement of a $2 \mathrm{MW}$ wind turbine is examined essentially the pitch control and speed control is quickly investigated by considering the turbine and the generator model by utilizing MATLAB 2018®b.
\end{abstract}

Keywords: MATLAB 2018®b, Control, Renewable Energy, Pitch Control, Turbine Load, Speed Control

\section{Introduction}

In nature different renewable energies are available but based on the abundance wind and solar energy are the most popular renewable energies in our world. Based on wind energy we study the horizontal axis wind turbine to extract the maximum power from the designed turbine and the installed machine around north of Ethiopia in Mekele city of specific area known as Ashegoda wind farm [11].

Wind turbine need proper controlling systems. In keeping with turbine classification supported their hub axis horizontal axis wind turbines need to be directed to face the wind.

The rated wind speed has different working parameters based on technical information on the wind turbine machine. It can be expressed as the turbine output at a specific wind speed during operation. Mainly major wind extracting machines generates the rated wind speed with a rated speed between 9 $\mathrm{m} / \mathrm{s}$ and $16 \mathrm{~m} / \mathrm{s}[2]$.

\section{Wind Turbine Control Mechanisms Stall Control}

Wind turbines with a stall controlling system having blades firmly fixed to the hub at a certain angle of attack. The essence of stall control is that the rotor airfoils lose the lift force called stalling as the wind speed increases beyond the designed limit. Power is controlled by progressive loss of rotor efficiency as stall extends over the rotor blade as the wind speed increases [13].

\subsection{Passive Stall Control}

The control system limits the output during high wind applied at a constant pitch turbine and these high speed wind drives the generators. The speed increases following the angle of attack to run in a constant speed

On the far side a selected angle of attack, the raise force decreases inflicting the rotor potency to drop. This can be AN 
intrinsic property and dispenses with the requirement for a posh system and moving components. The raise force are often additional reduced to limit the ability output at high winds by properly shaping the airfoil profile to make turbines on the airfoil facet not facing the wind [9].

\subsection{Active Stall Control}

Active stall management is a combination of the above 2 systems. At low and medium wind speeds, the blades square measure pitched sort of a pitch-controlled turbine; once the turbine reaches rated capability, the turbine can turn in the other direction so as to create the blades get in a deeper stall [3].

\subsection{Pitch Angle Control}

The device change the pitch perspective of the blades in accordance the version of wind velocity with pitch controlling device. it's potential to recognize a excessive efficiency with the aid of using unceasingly orienting the blade in the path of the relative wind on a pitch controlling device gadget due to the fact the wind velocity exceeds its rated velocity the blades place unit little by little grew to become concerning the longitudinal axes and out of the wind to increase the pitch perspective this reduces the mechanics efficiency of the rotor and additionally the output electricity will growth as soon as the wind velocity exceeds the secure restriction for the device, the pitch perspective is therefore changed that the capacity output reduces to 0 and additionally the gadget shifts to the stall mode. as soon as the air present day passes the pitch perspective is reset to the traditional function and additionally the wind turbine is restarted at ordinary wind speeds. The blade pitch perspective must preferably settle to a really well worth at that output electricity equals the rated electricity.

The enter variable to the pitch controller is that the error sign bobbing up from the big difference between the output electric powered electricity and reference power. The pitch controller operates the blade mechanism to trade the pitch angle. Throughout operations beneath the device endeavors to pitch the blade at companion diploma perspective that maximizes the rotor potency. The generator must be capable to take in the mechanical energy output and supply to the load. Thus the generator output energy has to be at the identical time adjusted.

In pitch controlling mechanism the turbine rotor blades regulate the facility extraction from the rotor by incessantly adjusting the pitch angles of the blades consistent with the incoming wind speed, so as to scale back or increase the lifting forces generated by the blade surface sections and thereby regulate the electrical power generated [13].

\section{Power Control}

A flow air through a unit area perpendicular to the wind direction is the kinetic energy which expressed as $\frac{1}{2} V^{2}$ per mass flow rate. Air stream flowing through an area $A$ the mass flow rate is $\rho \times A \times V$, therefore the power in the wind is equal to [4].

$$
P=\rho \times A \times V \times \frac{1}{2} V^{2}=\frac{1}{2} \times \rho \times A \times V^{3}
$$

Where

$\rho=$ is the air density $\left(\mathrm{kg} / \mathrm{m}^{3}\right)$,

$A=$ the area $\left(\mathrm{m}^{2}\right)$

$V=$ the wind speed $(\mathrm{m} / \mathrm{s})$, and

$P=$ the power of the wind (watts or $\mathrm{J} / \mathrm{s}$ ).

Power accessible from the wind could be operate the cube of the wind speed. Which means doubling of the wind speed provides eight times the ability output from the wind turbine. Therefore, turbines should be designed to support higher wind masses than those from that they'll generate electricity, to stop them from injury. Between $10 \mathrm{~m} / \mathrm{s}$ and $15 \mathrm{~m} / \mathrm{s}$ wind speeds the best potency in wind turbines reached. the ability output of the rotor should be controlled once the wind speed is higher than $15 \mathrm{~m} / \mathrm{s}$ the dominant is employed to scale back driving forces on the rotor blades and therefore the load on the complete turbine structure, [13].

\section{Basics of Control System}

In traditional operation all sizeable turbine systems in use to supply electricity have active management systems that deem computers [1].

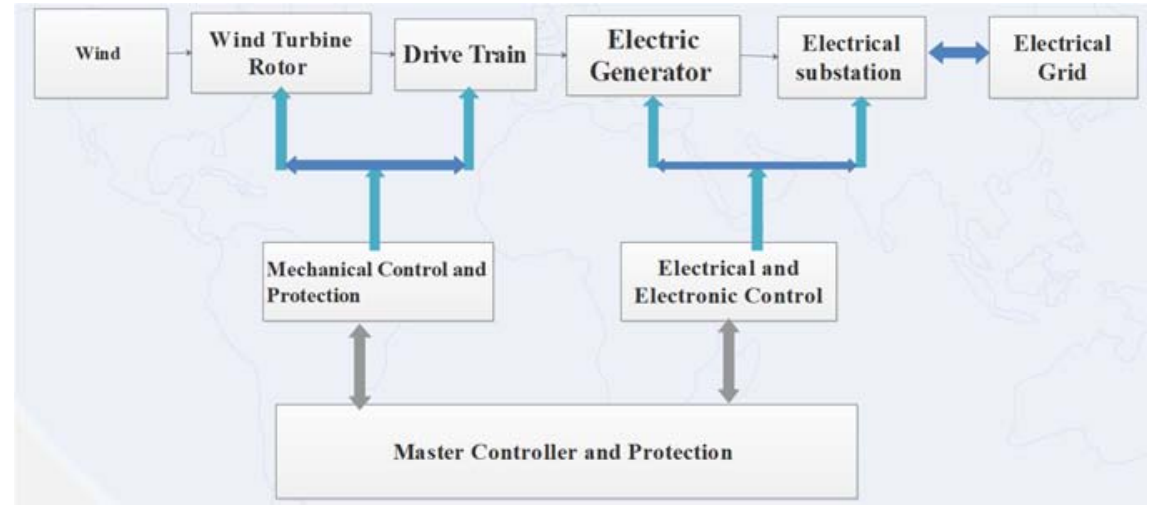

Figure 1. Generalized WT Control Diagram. 
The overall management of operation is delineate as higher-up management and this level of management addresses choices regarding start-up, shutdown, yawing braking procedures and responses to faults that don't seem to be at a level to trigger safety system actions [8].

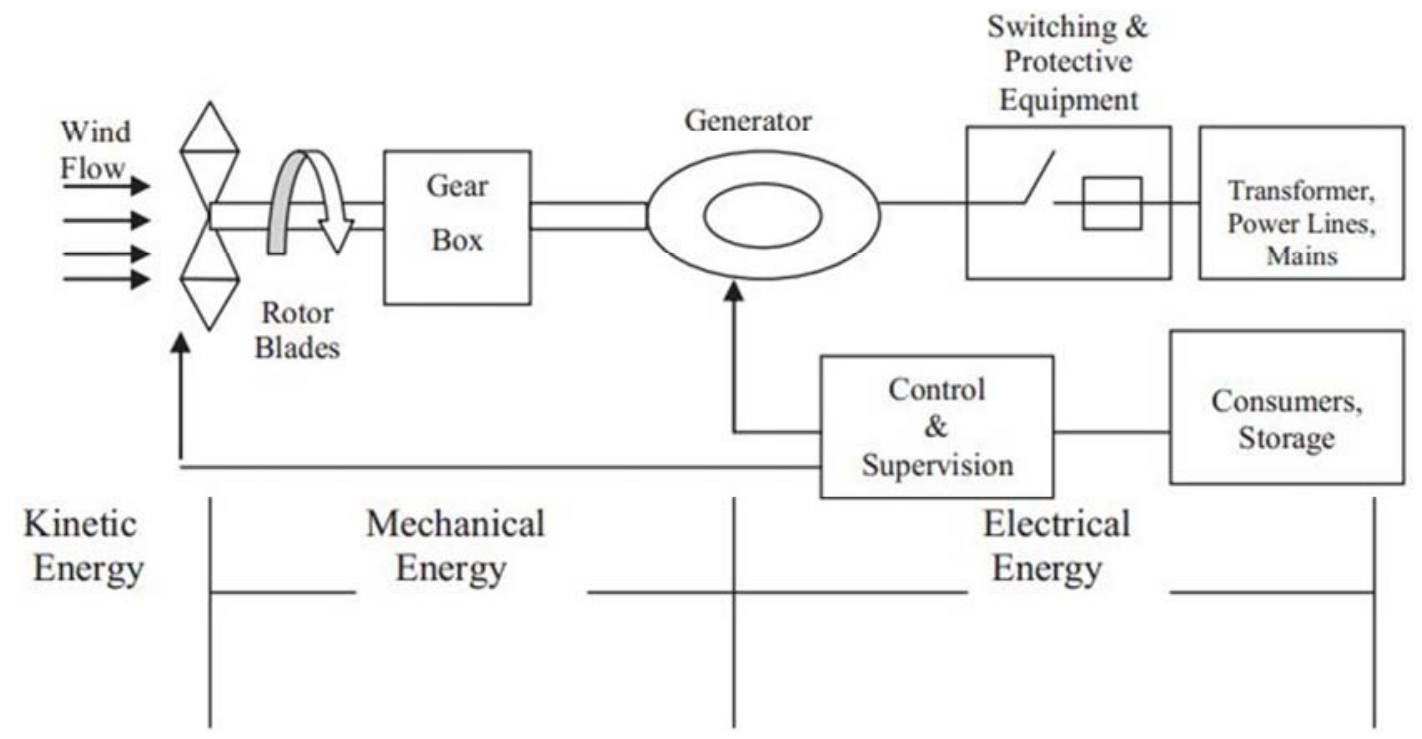

Figure 2. Power Transfer in Wind Energy Converter.

Wind turbine management systems are generally divided, functionally if not physically, into 3 separate parts:

A controller that controls varied wind turbines during a powerhouse,

A higher-up controller for every individual wind turbines, and

Separate dynamic controllers for the varied wind turbines subsystems in every wind turbine.

The wind farm controller, often called a supervisory control and data acquisition (SCADA) system, can initiate and shut down turbine operation and coordinate the operation.

The main control objectives are [15].

Reliability and availability
Energy capture maximization

Mechanical load and fatigue attenuation

Provide damping

Energy quality and grid stability

The wind park controller, typically known as a superior management and knowledge acquisition (SCADA) system, will initiate and pack up rotary engine operation and coordinate the operation. The main management objectives square measure [15]. Reliability and availableness Energy capture maximization Mechanical load and fatigue attenuation Provide damping Energy quality and grid stability

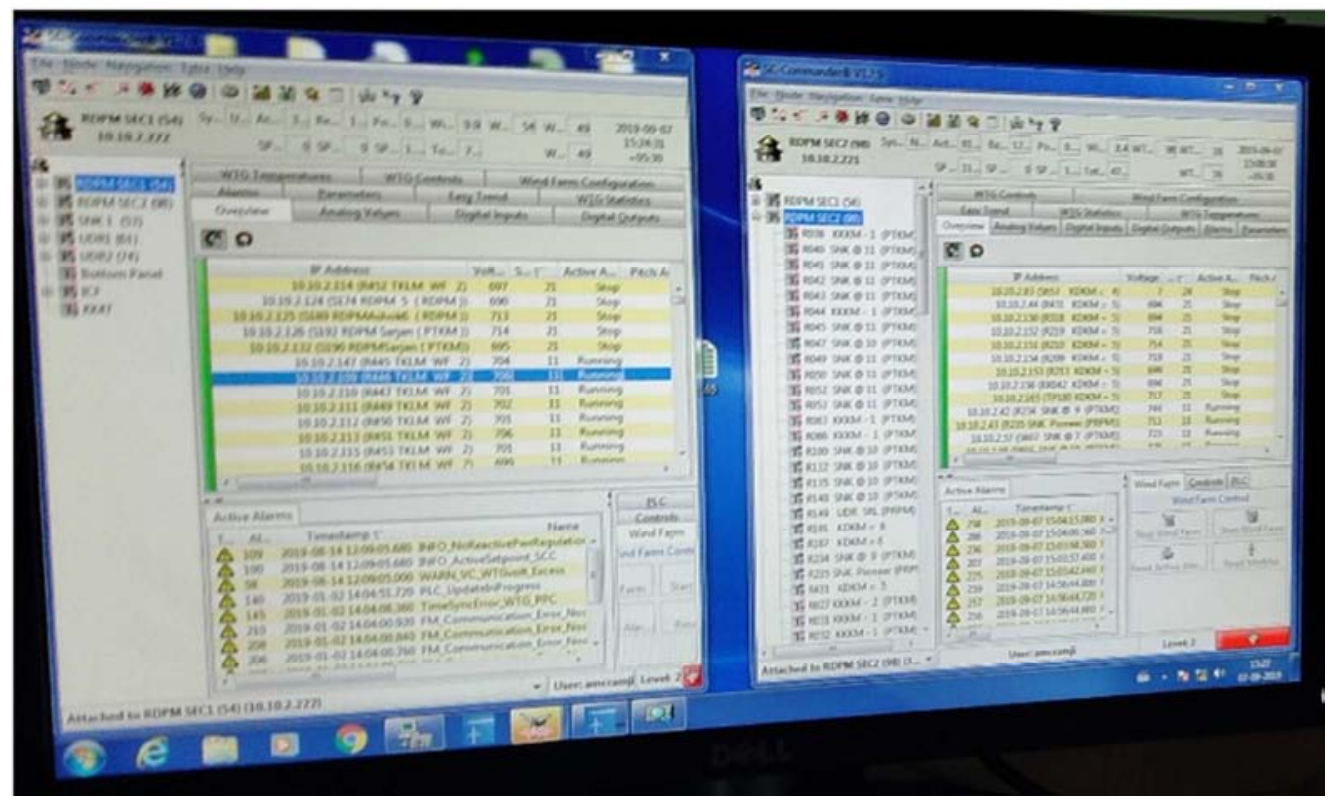



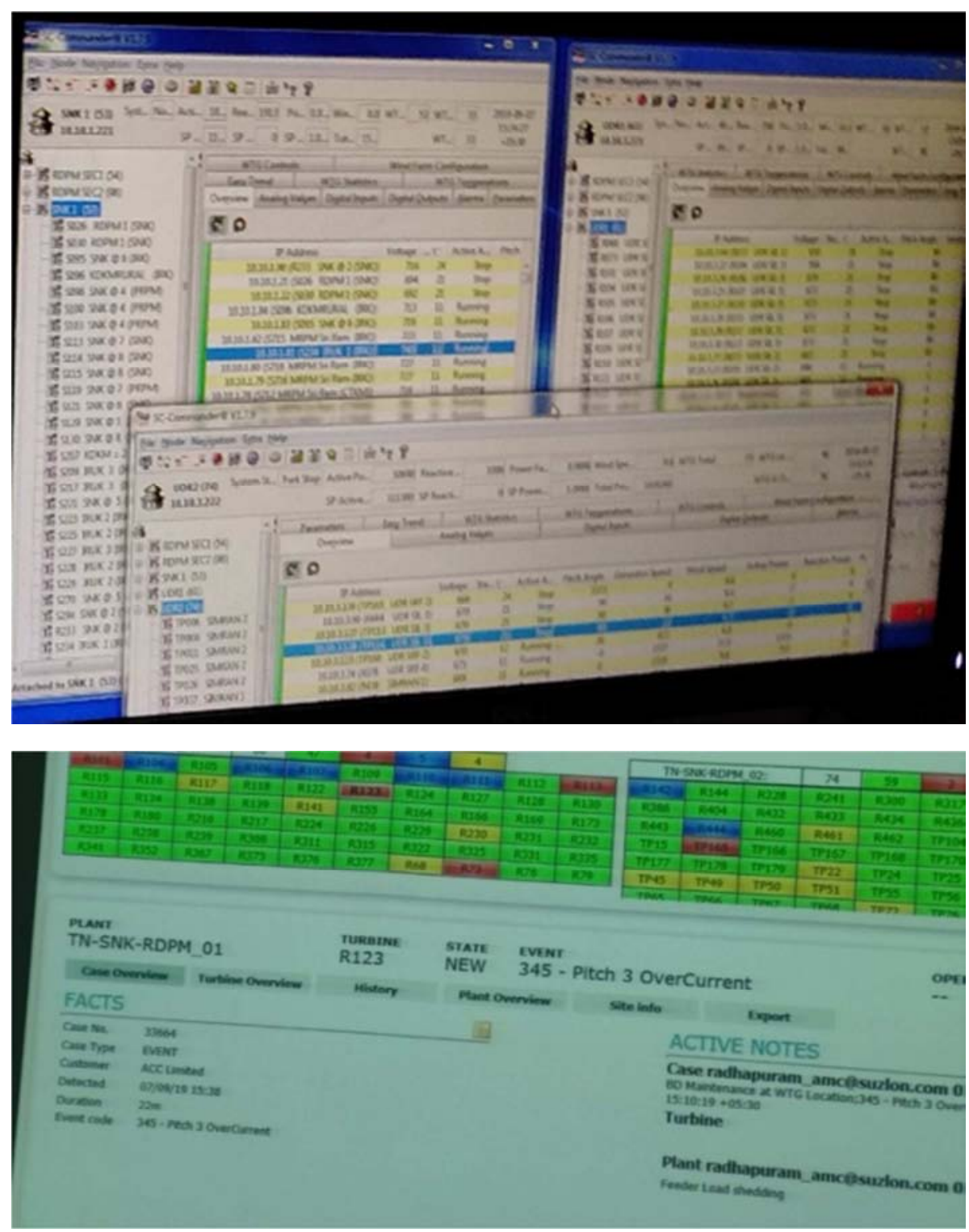

Figure 3. SUZLON Wind Farm Controlling Using SCADA India.

Wind turbine control system must ensure the quality of the power supplied, including the ability to

React to sudden voltage dips

Avoid power flicker

Correct the power factor

Contribute the grid frequency stability

Regulate the voltage and

Provide low harmonics content

\section{Control Strategies}

There are three main strategies for regulating the amount of power captured by the rotor which discussed in the introduction part.

Passive stall control or fixed pitch

Variable pitch control

Active stall control

When machines get larger and the load's become greater there is a trend toward pitch control and active stall control [10].

\subsection{Passive Stall Control}

For a passive stall-controlled WTs, the generator reaction torque regulates rotor speed below rated operation this indicates region 1 and 2 from figure to maximize energy capture whereas above rated operation region 3 rotor speed is controlled by deliberately including stall over a specific wind speed. In this manner the power delivered by the rotor is limited at high winds thanks to a design of the blades that provokes a loss of efficiency. Additionally, in this manipulate the pitch attitude is fixed, and the tip brakes are the solely section of the blade that can be rotate with the purpose of spilling off the spare strength to shut down the Wind turbine [4].

\subsection{Variable Pitch Control}

During pitch control the blades alter the energy delivered by way of the rotor both through pitching the blades towards the wind to maximize power seize or by means of pitching to 
feather to discard the extra of energy and make sure the mechanical obstacles are no longer exceeded.

At rated operation from above figure 4 region 3 the aim is to maintain power and rotor speed to their rated value. To achieve this the torque is held constant and the pitch is continually changed following the demand of the closed loop rotor speed controller that limits energy capture and follows wind speed variations. In contrast below rated operation regions 1 and 2 there is no pitch control and the blade is set to a fine pitch position to yield higher position to yield higher values of power capture while the generator torque turns off the machine simply by moving the blades (pitch angle) toward the feathered position which is the position perpendicular to the wind direction [10].

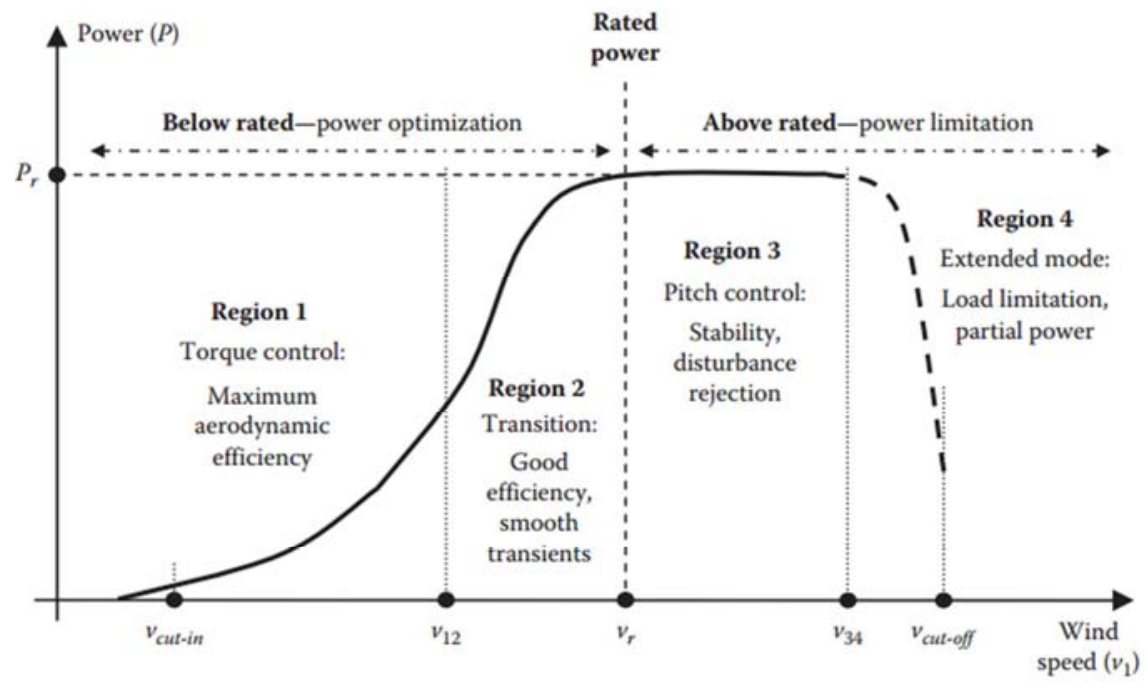

Figure 4. Power Curve of a Wind Turbine.

\subsection{Active Stall Control}

This approach is a mixture of stall and pitch control. The blades are designed in a comparable manner as the stall manipulate blades, however the complete blade is grew to become ninety diploma to modify the pitch for that reason the tip of the blade brakes used in passive stall are no longer required. In these approach the blades are circled solely via small quantities and much less often than in the pitch manipulate machines the thinking is to pitch the blade steadily with a terrible pitch perspective "pitch to stall" in order to optimize the overall performance of the blades over the vary of wind speeds particularly with low speeds. The energy manage approach adjusts the quantity of blade that is at stall to compensate the savings of electricity output [3].

\subsection{Control System}

Four regions and two areas are indicated in the figure 4. The power P of the WT that is the actual power supplied to the grid which is the incoming wind power minus losses separates the graph into two main areas: below and above rated power $p_{r}$ below rated power or below rated wind speed, $v 1<v r$ the WT produces only a fraction of its total design power and therefore an optimization strategy to capture the maximum amount of energy at every wind speed needs to be performed. On the other hand, above rated power or above rated wind speed, $v r<v 1$ where the wind has more power than the rated power $p_{r}$ a limitation strategy to generate only the rated power is required. The four regions of the power curve present the following characteristics:

Region one: the Torque control lowest wind usually between $\mathrm{v}$ reduce in $=3-4 \mathrm{~m} / \mathrm{s}$ and $\mathrm{v} 12=7-8 \mathrm{~m} / \mathrm{s}$ the goal in this vicinity is to acquire the most aerodynamic efficiency. This is normally finished via capability of manipulating the electrical torque $\mathrm{Tg}$ in order to get a precise and pre constant ratio (optimum tip velocity ratio $\lambda_{\text {opt }}$ ) between wind pace and rotor speed. The most aerodynamics strength coefficient $C_{p}$ is achieved.

Region two transition: medium wind commonly between $v_{12}=7-8 \mathrm{~m} / \mathrm{s}$ and $v_{r}=11-13 \mathrm{~m} / \mathrm{s}$ in this location it is now not feasible to achieve the favored tip pace ratio due to the fact the rotor velocity is close to to its most value. The torque should be elevated till the turbine reaches its rated power. This is commonly completed via following a excessive slope torque/ rotor pace reference or through imposing a closed loop controller [15].

Region three Pitch control: excessive wind commonly between $v_{r}==11-13 \mathrm{~m} / \mathrm{s}$ and $v_{34}=20-25 \mathrm{~m} / \mathrm{s}$ the blades have to go the pitch perspective $\beta$ in order to restrict the incoming power, manipulate the rotor pace $\Omega r$ and decrease the mechanical hundreds at the identical time. An necessary price discount and lifestyles running augmentation can be completed if load attenuation is focused as main goal when designing the controller or if the blade impartial manage approach to decrease hundreds is performed.

Region four extended mode: very high wind typically between $u_{34}=20-25 \mathrm{~m} / \mathrm{s}$ and $v_{\text {cutoff }}=25-30 \mathrm{~m} / \mathrm{s}$ although not very common an extended mode in very high winds can be obtained by means of varying the pitch closed loop performance through a rotor speed omega $\mathrm{r}$ limitation, the extreme loads can be reduced [15]. 


\section{Controller}

The main features of the controller are as follows: Data acquisition input/ output system. Inputs are indicators coming from the sensors whereas outputs are alerts going to the actuators.

Signal processing

Evaluation of the state of the system, execution of control laws, and supervision.

Handling data acquisition for the supervisory control and data acquisition (SCADA) system for storage maintenance and remote operating purpose [15].

\section{Synchronized Wind Turbine Control}

The trend in the wind energy industry is to install wind turbines in large concentrations with hundreds of megawatts of power capacity. Wind farms of this size are often connected directly to the transmission grid, replacing traditional power plants. This means that wind turbines are required to behave as active controllable components in the power system. Such large wind farms need to meet very high technical demands, such as to perform frequency and voltage control, to regulate power and provide quick responses during transient and dynamic situations in the power system [3].
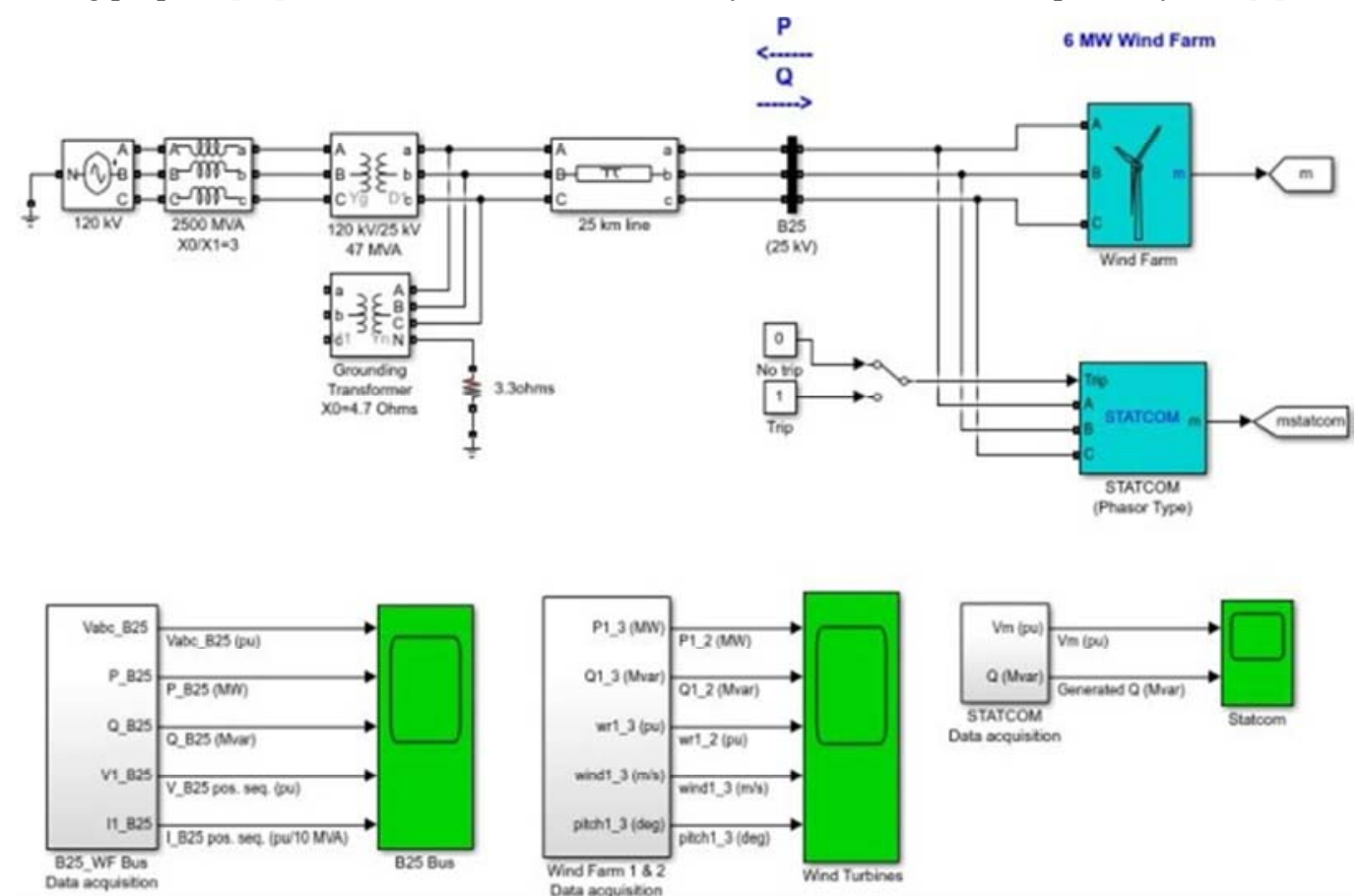

Figure 5. $6 M W$ Wind Farm MATLAB Output Controlling System.

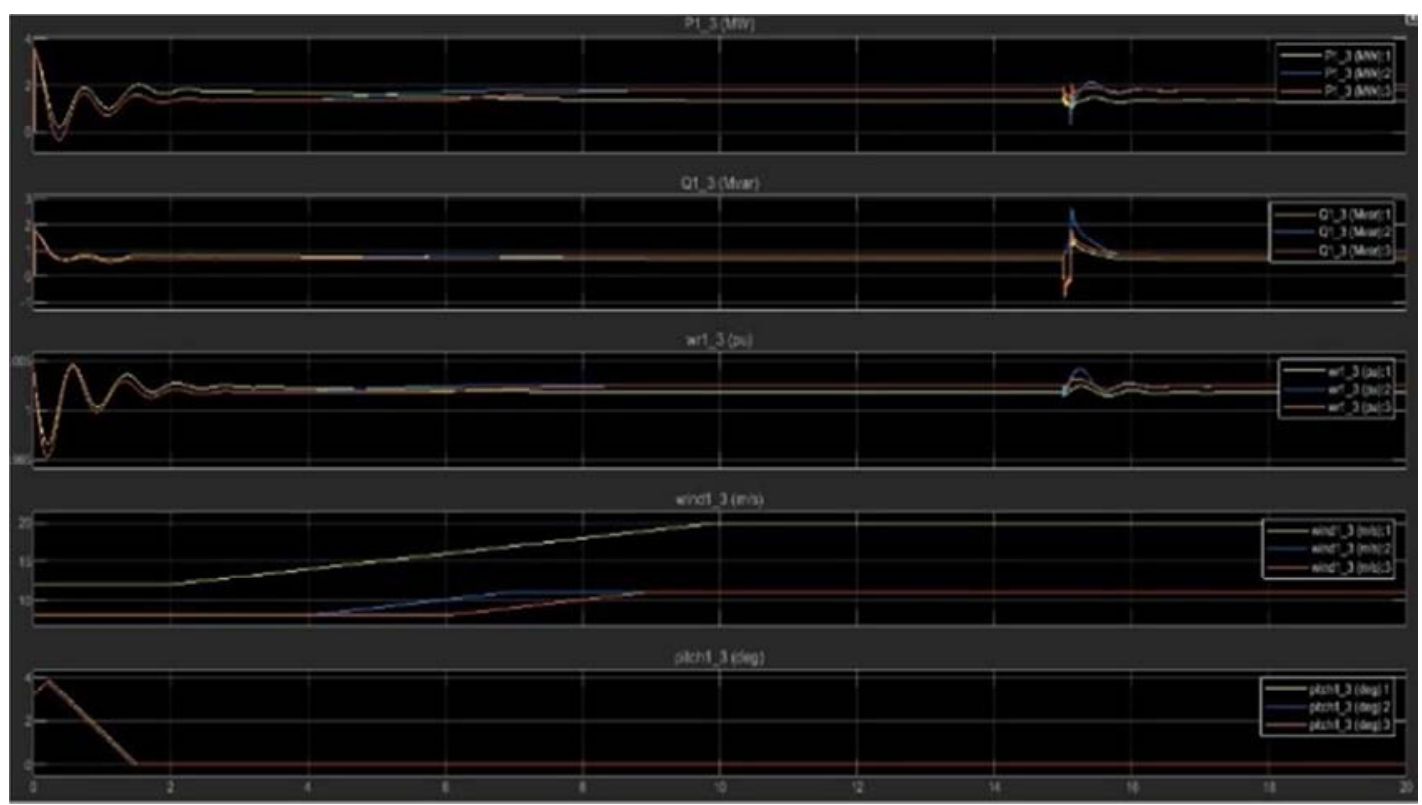

Figure 6. Power, wind speed and Pitch Controlling of each turbine on MATLAB. 
The MATLAB output shows that with three different colored response indicators that are responsible to indicate the power production and blade pitching system based on the wind direction. Even if the power production is fluctuating due to wind velocity deference by controlling the turbine power output with pitch angle the power shows a constant graph.

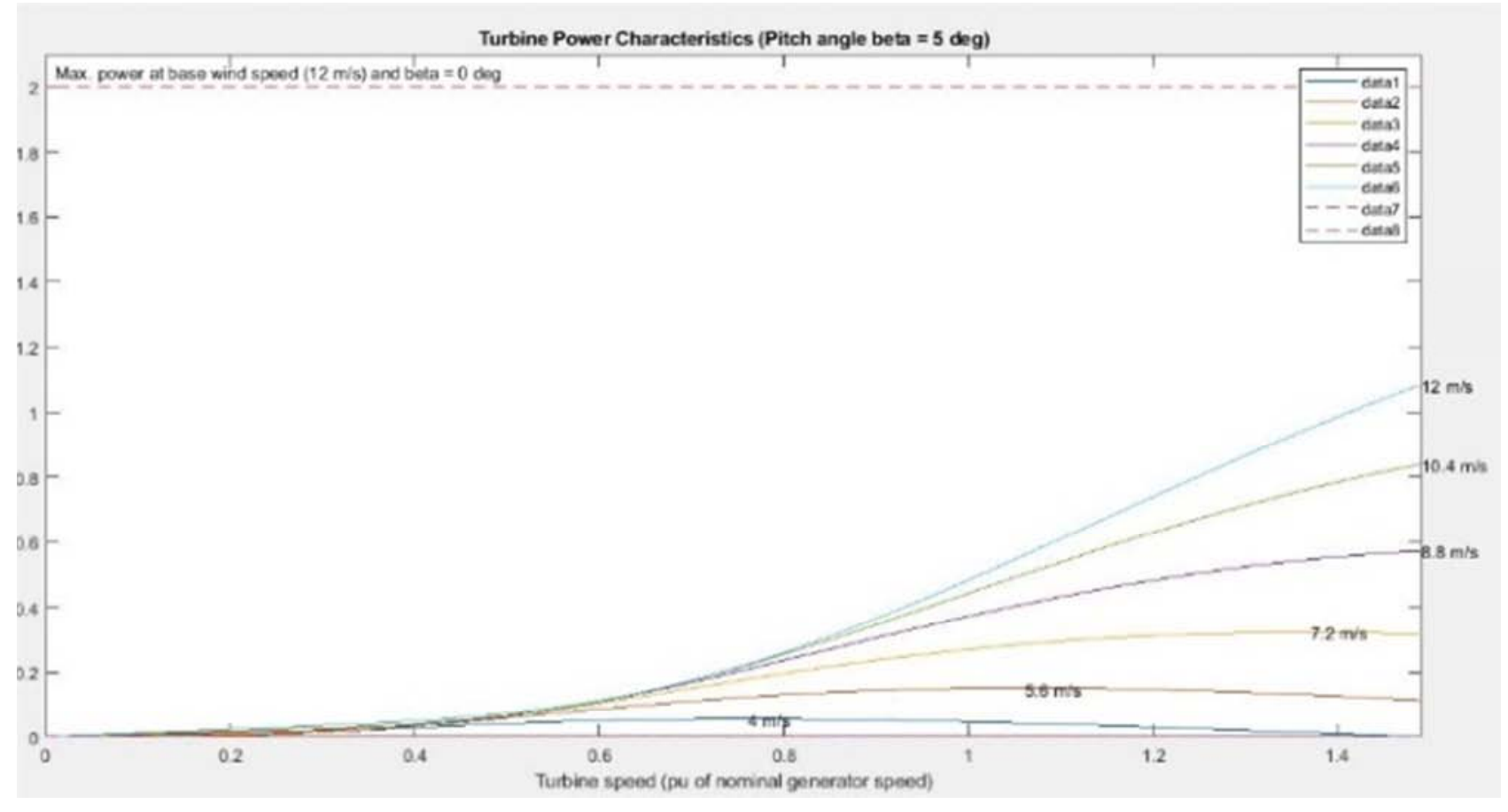

Figure 7. Turbine Power Characteristic Curve.
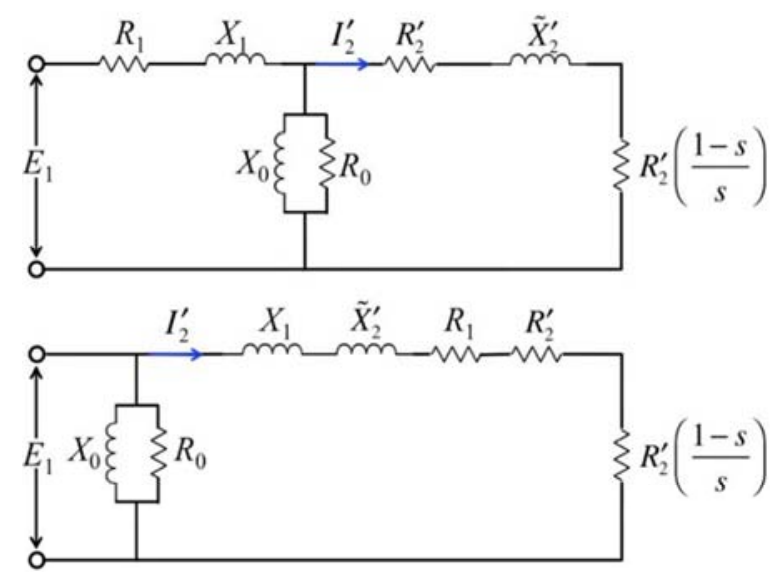

$$
\begin{array}{ll}
\text { Mechanical Torque: } & \text { Mechanical Power: } \\
T=\frac{3 I_{2}^{\prime 2}\left(R_{2}^{\prime} / s\right)}{\Omega_{s}} & P_{m}=3 I_{2}^{\prime 2} R_{2}^{\prime}\left(\frac{1-s}{s}\right)
\end{array}
$$

Figure 8. Approximate Equivalent circuit.

\section{Mathematical Modeling}

The mathematical modeling emphasis basically on the wind turbine main control loops described as follows [1].

Torque is

The power $\mathrm{p}$ generated by the WT and injected to the grid

$$
P=\frac{1}{2} \rho A_{r} C_{p}(t) v_{1} t^{3}=T_{r}(t) \Omega_{r}(t) \eta
$$

Where

$T_{r}=$ mechanical torque at the shaft due to the wind $\Omega_{r}=$ rotor speed

$\rho=$ air density

$A_{r}=$ rotor effective surface

$v_{1}=$ undistributed upstream wind speed $\eta=$ mechanical and electrical efficiency $C_{p}=$ aerodynamic power coefficient

And

$$
C_{p}(t)=f[\lambda(t), \beta(t)]
$$

Where $\lambda=$ the tip speed ratio defined as a function of the rotor radius $r_{b}$ rotor speed $\Omega_{r}$ and wind speed $v_{1}$ so that

$$
\lambda(t)=\frac{r_{b} \Omega_{r}(t)}{v_{1}(t)}
$$

The electrical torque $T_{g}$ is manipulated by control system below rated power in region 1 and 2 to achieve the maximum aerodynamic efficiency $C_{p m a x}$. This strategy aims to keep the relationship between wind speed $v_{1}$ and rotor speed $\Omega \mathrm{r}$ optimal as long as possible. It modifies the rotor speed by changing the electrical torque $T_{g}$ against the mechanical torque $T_{r}$ producing an acceleration torque to follow the wind speed changes and keep $\lambda=\lambda o p t$

The mechanical torque $T_{r}$ at the shaft of the rotor due to the wind speed is.

$$
T_{r}(t)=\frac{0.5 \rho A_{r} C_{p}(t) v_{1} t^{3}}{\Omega_{r}(t)}
$$


Hence introducing $C_{p}=C_{p \max }$ and $\left[r_{b} \Omega_{r}(t) / v_{1}(t)\right]=$ $\lambda=\lambda$ opt the resulting torque for maximum power capture at every wind speed is demanded electrical torque $T_{g}$ as given by the following two equations

$$
\begin{gathered}
T_{g}(t)=\left(\frac{0.5 \rho A_{r} r_{b}^{3} C_{p \max }}{\lambda_{o p t}^{3}}\right) \Omega_{r} t^{2}=K_{a} \Omega_{r} t^{2} \\
K_{a}=\frac{0.5 \rho A_{r} r_{b}^{3} C_{p \max }}{\lambda_{o p t}^{3}}
\end{gathered}
$$

Where

$C_{p \text { max }}=$ The maximum power coefficient obtained at $\lambda o p t$ equations show a very simple and useful expression to set up the torque at below rated region.

The electrical torque $T_{g}$ obtained from equation is not usually enough to cover the entire zone below the rated value such as region 1 and 2 the whole region beneath the rated cost such as location 1and two due to the fact the rated rotor pace is reached earlier than accomplishing the most torque. Hence a one of a kind approach desires to be carried out to amplify the torque till it reaches its most rated price generally following a excessive torque or rotor pace reference or with the aid of imposing a closed loop controller at area two [2].

\section{Power Curve Input \& Power Coefficient and Mean Power Calculation}

By a specific control system and by using software program the estimated wind turbine power curve can proofed whether it meet the standard power curve or not and also it shows the rated turbine power in steady wind condition in kilo watts based on the given wind speed mainly the cut in and cut out speeds and the rotor diameter of the blade. The cut in and cut out speeds are the recommended values used for large wind turbine design in the program. The result shows that at rated velocity the turbine generated the rated power as shown in Figure 9 in the right side and the red levels shows the turbine efficiency which shows around $47 \%$.

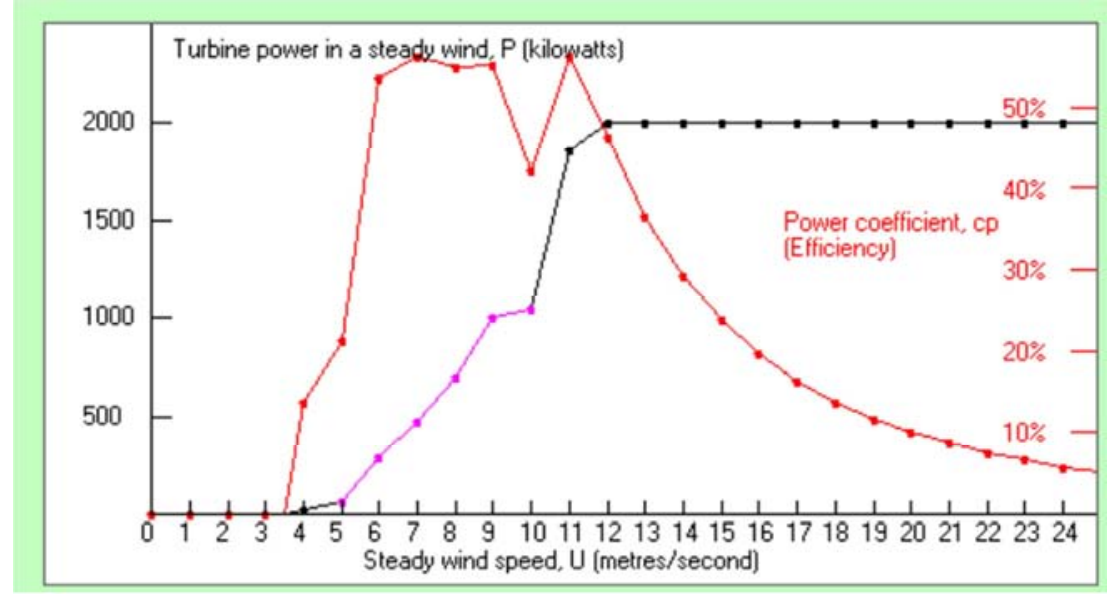

Figure 9. Power Curve Input \& Power Coefficient and Mean Power Calculation.

The controlled and optimized power curve during this study shows the following power curve.

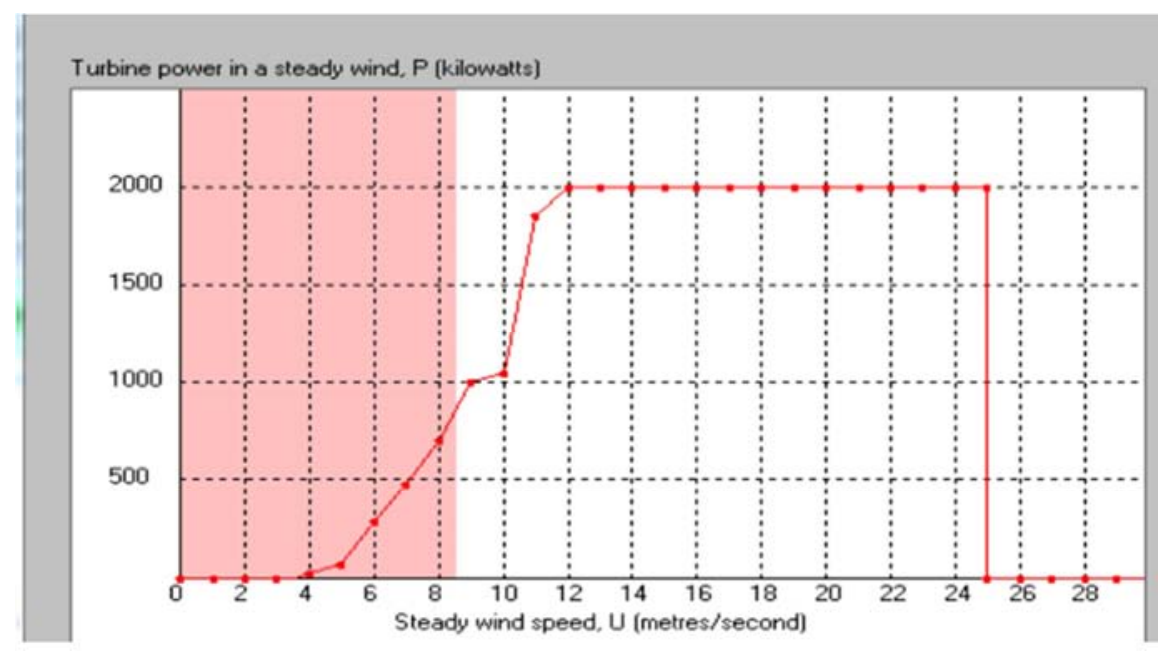

Figure 10. Optimized power curve. 


\section{Conclusion}

Large horizontal axis wind turbine an appropriate control system is needed in order to fulfil the standard controlling system curve or the power curve of a wind turbine. This appropriate control system has a lot advantage based on productivity and to avoid system failures of a wind turbine generator. If the wind turbine generators is working at maximum speed or above the cut of speed the turbine will blow and leads to economic crises. The optimum control system will prove that the working wind speeds such as the cut in speed, the working speed and the cut out speed are safely operated based of the system control.

This paper presents the basic control system for a wind turbine in order to operate safely to produce maximum power extraction from wind. And to maximize the wind turbine machine life. Each design analysis are shown based on MATLAB 2018b Simulink software with a required parameters based on existing working wind turbine generators from kayatar, Chennai, India and Ethiopia Adama and Ashegoda wind farms. This study will fix the power generation control problems in Ethiopia wind farms specially in Ashegoda wind farm which is located in the northern part of Ethiopia in Tigray region and this farm has a big problem in power controlling system during to high speed winds and this problem Leeds most of the turbines are not functional for long times.

\section{Acknowledgements}

I would first like to thank my supervisor, Belete Sirahbizu Yigezu $(\mathrm{PhD})$ Assistant Professor and University-Industry Linkage Director; his workplace turned into continually open on every occasion I bumped into a trouble spot or had a question approximately my paper. He always allowed this paper to be my personal work and additionally for his valuable steerage and encouragement at some stage in this examine and thanks for his patience and trust throughout the study.

\section{References}

[1] David A. Spera, Wind Turbine Technology Fundamental Concepts in Wind Turbine Engineering, Second Edition 2009, ASME Press (American Society of Mechanical Engineers).

[2] James F. Manwell, Jon G. McGowan, Anthony L. Rogers Wind energy explained theory, design and application 2002, Wiley.

[3] Hansen, A. C. Butterfield, C. P., Aerodynamics of Horizontal Axis Wind Turbines, Annual Review of Fluid Mechanics, 1993, Vol. 25.

[4] Le Gourieres, D., Wind Power Plants, Theory and Design, 1982, Pergamon Press.
[5] Glauert, H., The Elements of Airfoil and Airscrew Theory, 1983 Cambridge Univ. Press.

[6] Timmer, W. A., van Rooy, R. P. J. O. M., "Thick Airfoils for HAWTs", Journal of Wind Engineering and Industrial Aerodynamics, Vol. 39, 1992.

[7] Barlas, T.; Lackner, M. The Application of Smart Structures for Large Wind Turbine Rotor Blades. In Proceedings of the Iea Topical Expert Meeting; Delft University of Technology: Delft, The Netherlands, 2006.

[8] Ahlstrom, A. Emergency stop simulation using a finite element model developed for large blade deflections. Wind Energy 2006.

[9] Chandrala M., Choubey A. Gupta B., 2012. Aerodynamic analysis of horizontal axis wind turbine blade. Journal of Engineering Research and Application 2.

[10] Benini E., Toffolo A., 2005. Optimal design of horizontal-axis wind turbines using blade-element theory and evolutionary computation. Journal of Solar Energy Engineering.

[11] Adama I Wind farm Project Summary Report 2011.

[12] Case_study-ASHEGODA-WIND-FARM-rev-1.

[13] Ethiopia Wind Resource Poster Landscape WBESMAP Apr 20162 .

[14] Ethiopian Electric Power Corporation (EEPCo). Strategic management and programming. Facts in brief; 2011.

[15] Wei Tong, wind power generation and wind turbine design, 2010 WIT press.

\section{Biography}

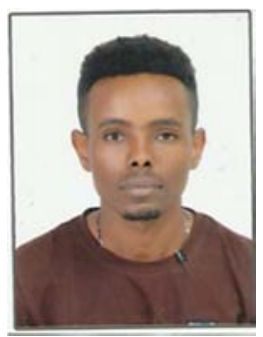

Gizachew Dereje Tsega

University of Gondar

2017/18-2019 MSc, Mechanical Engineering (Design) Addis Ababa science and Technology University,

2010-2015 BSc, Mechanical Engineering from BahirDar Institute of Technology,

$3^{\text {rd }}$ Special international Conference training "Design Installation \& Maintenance of Small Wind Turbine" National Institute of Wind Energy, Chennai, India.

Publications

Gizachew Dereje \& Belete Sirahbizu "Design and Analysis of 2MW Horizontal Axis Wind Turbine Blade" International Journal of Innovative Science, Engineering and Technology, 2019, 136157

Gizachew Dereje Tsega, Belete Sirahbizu Yigezu, Upwind 2MW Horizontal Axis Wind Turbine Tower Design and Analysis, Automation, Control and Intelligent Systems. Vol. 7, No. 5, 2019, pp. 111-131. 